\title{
EXPERIENCIAS EN DEFENSA DEL DERECHO DE TODA NIÑA O NIÑO AL
}

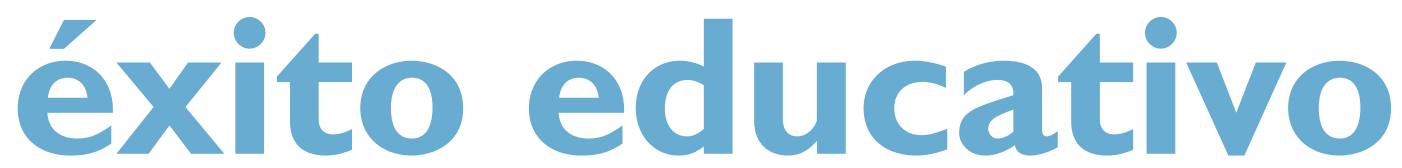

DOI

\section{Ramón Flecha García}

Catedrático de Sociología de la Universidad de Barcelona ramon.flecha@ub.edu n nuestras sociedades hemos alcanzado el derecho a la salud en su doble componente. Toda persona tiene derecho a acudir a un centro hospitalario donde no sólo se le va a atender sino que también se le van a aplicar aquellos tratamientos, que la comunidad científica internacional ha probado con evidencias científicas, que tienen los mejores resultados para curar su enfermedad.

En educación hemos alcanzado parte de ese derecho: todo niño o niña puede ser atendida en un centro educativo. Sin embargo, no hemos logrado todavía el derecho a que se le apliquen las actuaciones educativas que, según las evidencias recogidas por la comunidad científica internacional, generan los mejores resultados.

La Fundación SM, en la edición “Educar lo es todo 2013”, ha premiado diez experiencias que representan buenas prácticas educativas para la lucha contra el abandono escolar temprano y el fracaso escolar. Éste es el merecido reconocimiento a todas ellas por estar realizando un extraordinario trabajo no sólo por la defensa del igual derecho de toda niña o niño al éxito educativo, sino por estar demostrando que incluso en los peores momentos se pueden dar grandes avances hacia ese derecho. En nuestro contexto se ha llegado a valorar durante mucho tiempo las experiencias educativas con grupos vulnerables por lo interesantes o innovadoras que les resultaban a quienes no tenían ese problema. Incluso se ha llegado a decir que lo importante de esas experiencias no eran los resultados, sino los procesos. Esta afirmación llevaba implícita y explícitamente una crítica al éxito educativo y a la base científica que es imprescindible para lograr superar los problemas de abandono escolar temprano o fracaso escolar.

Considerando las diferentes experiencias premiadas podemos destacar un eje común en todas ellas: el énfasis en el éxito educativo como herramienta clave para la superación del abandono escolar temprano y el fracaso escolar. De igual manera, llaman la atención otros tres elementos que estas diez experiencias comparten, como el acento en el trabajo cooperativo entre el alumnado y el fomento y diversificación de las interacciones; la coordinación con el entorno y la implicación de las familias; y el necesario cambio de expectativas para lograr la transformación social y educativa que lleva a la superación de las desigualdades que los grupos más vulnerables de la sociedad sufren.

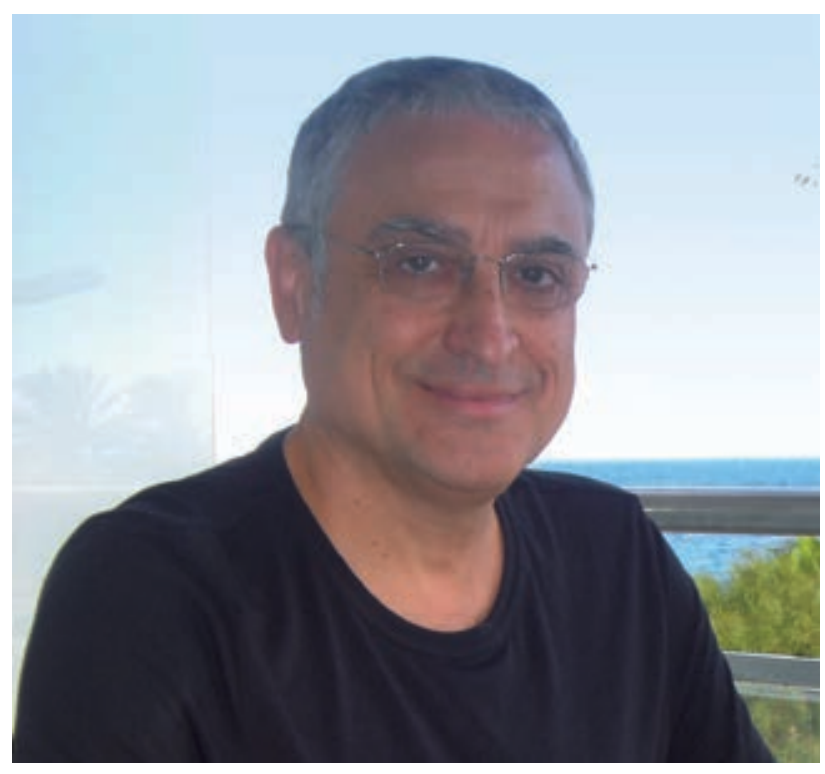

Ramón Flecha García.

Presentamos la
importante labor de
las diez experiencias
premiadas en la edición
"Educar lo es todo"
de la Fundación SM
en el año 20l3. Desde
diferentes ámbitos
y niveles educativos,
estas experiencias
son una muestra de
cómo en los peores
momentos se pueden
dar grandes avances
hacia la consecución del
derecho de toda niña o
niño al éxito educativo.




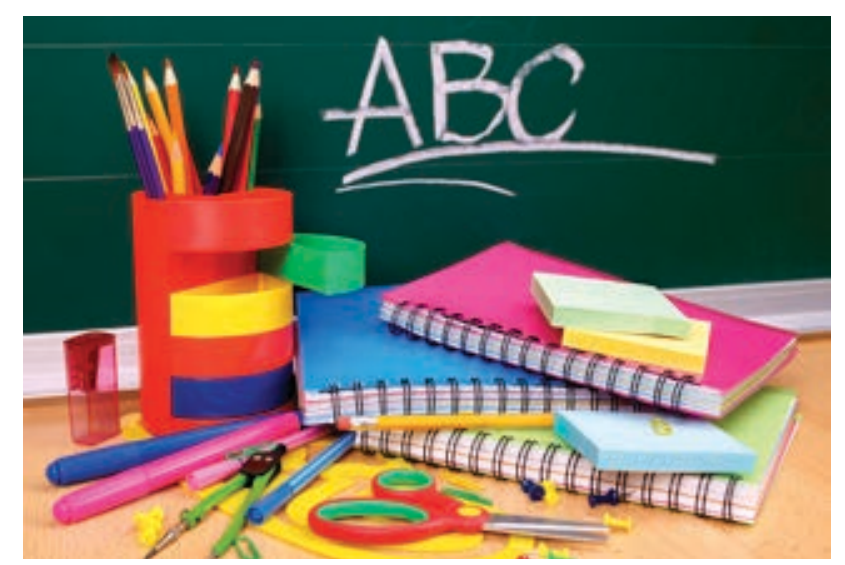

El primero de estos aspectos en común hace referencia al fomento de las interacciones, de la cooperación entre compañeros y compañeras y el énfasis en el aprendizaje instrumental como imprescindible para el éxito educativo. En esta línea encontramos la experiencia del proyecto "Regreso a Ítaca" desarrollado en el IES Gran Canaria de Las Palmas de Gran Canaria. Además de destacar el gran compromiso del claustro de profesorado por lograr los cambios necesarios para dotar al alumnado de las herramientas necesarias para mejorar tanto a nivel académico como personal, han logrado a través del proyecto fomentar los trabajos cooperativos de los estudiantes y, en consecuencia, la atención y el respeto por el trabajo de sus compañeros y compañeras. De este modo, la implicación del alumnado en el centro ha aumentado de forma muy significativa a través de la creación de una red sólida de actuación común.

También en esta misma línea, podemos hacer referencia a la gran labor que desde la parroquia de Santo Domingo de la Calzada de Madrid se está desarrollando en El Gallinero. Además de entender la educación como elemento imprescindible para superar las graves condiciones de desigualdad en las que viven estos niños y niñas, centran sus esfuerzos y ponen el énfasis en la lectoescritura y las matemáticas como aspectos clave para obtener éxito educativo. Además, la familia desempeña también un papel importante en este proceso de transformación educativa. Su trabajo de alfabetización en las chabolas no es un simple parche que suple las necesidades de un colectivo que vive en un entorno de gran marginalidad, sino que se entiende también como una manera de fomentar la mejora educativa de las niñas y los niños.

El énfasis en la mejora de los resultados académicos y de la convivencia es también uno de los puntos destacados del trabajo que se hace desde el CEIP Antonio Machado de Mérida a través del desarrollo de actuaciones educativas de éxito avaladas por la comunidad científica internacional como, por ejemplo, los grupos interactivos. Con ello y durante este tiempo han logrado mejorar los resultados académicos del alumnado, reducir el absentismo escolar del $40 \%$ al $16 \%$ y mejorar la convivencia dentro y fuera del aula. Las familias, entre otras personas adultas, entran en las aulas para ayudar al profesorado y evitar así que ningún niño o niña tenga que ser segregada de su aula, contribuyendo a su vez a la aceleración de sus aprendizajes y la mejora de la convivencia.

De hecho, esta vinculación entre el proceso educativo de los y las estudiantes con la implicación de las familias y del entorno destaca como el segundo de los aspectos que comparten estas experiencias premiadas. Por ejemplo, el colegio público La Paz, en Albacete, también a través del desarrollo de las actuaciones educativas de éxito, ha logrado un importante aumento de la matrícula de 80 a 256 alumnos, demostrando que estas actuaciones obtienen la mayor mejora de resultados en cualquier contexto en la que se apliquen. En La Paz decidieron aplicarlas todas a la vez y de forma conjunta, para lograr evolucionar de forma rápida, siendo uno de los aspectos clave la participación educativa de las familias y la comunidad. En este sentido, la oferta formativa del centro se ha abierto también a los familiares y a la comunidad, incluyendo actividades como, por ejemplo, alfabetización, matemáticas dialógicas, informática, inglés o tertulias literarias dialógicas. De este modo se demuestra lo que ya desde la investigación de mayor reconocimiento internacional se afirma, que la mejora del proceso de aprendizaje del alumnado está vinculada a los procesos formativos que sus familiares estén desarrollando en ese mismo momento.

Establecer lazos de cooperación y coordinación con las familias ha sido también uno de los trabajos vertebradores de la Asociación de Formación y Promoción Social Diversy y el CEIP Prácticas n. ${ }^{\circ}$ I de Málaga. De este modo, han logrado un aumento de la implicación de las familias en el proceso educativo de sus hijos. Uno de los ejes ha sido el establecimiento de unos objetivos compartidos entre el centro y el entorno que han llevado a la realización de actividades comunes en las que todos se implican. Se trata de otra experiencia que demuestra cómo, cuando las familias se sienten protagonistas de los procesos educativos de sus hijos e hijas, y comprueban que con su participación sus resultados mejoran, la implicación con el centro aumenta de forma muy significativa.

En este mismo sentido, la Asociación Arca de Noé de Valencia trabaja con el convencimiento de que los niños, niñas, jóvenes y familias del barrio de Nazaret tienen derecho a su desarrollo personal y social, poniendo como eje clave el aprendizaje. Su lucha contra el absentismo y abandono escolar se ha centrado no solamente en el niño o niña sino también en el trabajo de coordinación con sus familiares y con el centro educativo. Siguiendo la línea de la concepción actual de aprendizaje que pone el énfasis en la coordinación de interacciones, desde la asociación han apostado por el trabajo en red y la coordinación como clave de la mejora y de la necesaria transformación social, logrando resultados visibles. Prueba de ello es el hecho de que los antiguos niños y niñas del Arca piden ahora que sus hijos e hijas también puedan asistir.

También desde el trabajo del centro socioeducativo Naüm de las Hermanas de La Caridad de San Vicente de Paúl de Palma de Mallorca se ha puesto el 
énfasis en esta misma línea de enfatizar la implicación del entorno. El conjunto de programas que están desarrollando sirven a un objetivo común que es el de ofrecer oportunidades a los niños, niñas y jóvenes del barrio de Son Roca, dando especial prioridad al aspecto académico. En este proceso, han acentuado la implicación por parte de las familias en su programa de refuerzo, así como el establecimiento de una red en la zona con los centros de primaria y secundaria, el Centro de Atención Primaria o los servicios sociales, a la vez que con otras entidades del barrio como el club deportivo, la asociación de la tercera edad o la asociación de vecinos.

Finalmente, un tercer aspecto que hay que destacar entre estas diez experiencias es la necesaria transformación de las expectativas y de las opciones de futuro que se les ofrece a los colectivos más vulnerables de la sociedad. El programa "Promociona" lanzado desde la Fundación Secretariado Gitano en 2009 para avanzar en el éxito educativo del alumnado gitano (entendido como acabar con éxito la educación secundaria y continuar los estudios postobligatorios), abarca actualmente más de 1.200 alumnos y alumnas en todo el ámbito nacional. Se trabaja tanto desde las familias como a través de tutorías individualizadas con el alumnado y sus significativos resultados están contribuyendo al cambio de percepción que se está dando desde la sociedad hacia la situación educativa del pueblo gitano. Lograr los resultados que han obtenido desde entonces (la finalización con éxito de la etapa obligatoria del $77 \%$ del alumnado participante en el programa, del que un $96 \%$ continúa los estudios postobligatorios) ha sido posible también gracias a este cambio de expectativas. Seguir estudiando se vive y siente con orgullo desde las familias gitanas y como algo importante desde los propios alumnos, pues supone una de las principales bases para lograr un futuro mejor.

Ésta ha sido también parte de la tarea que se está desarrollando desde el Plan de Compensación Educativa del IES Antonio Domínguez Ortiz de Sevilla. Además de concebir su trabajo con el alumnado no desde el ámbito exclusivo del aula sino también con una proyección al exterior, han logrado cambiar la visión que tienen los y las estudiantes sobre su futuro, un cambio de expectativas clave para que tengan éxito en su trayectoria académica. Ofrecerles la posibilidad de no tener que reproducir las desigualdades de partida es uno de sus principales objetivos, apostando así por la

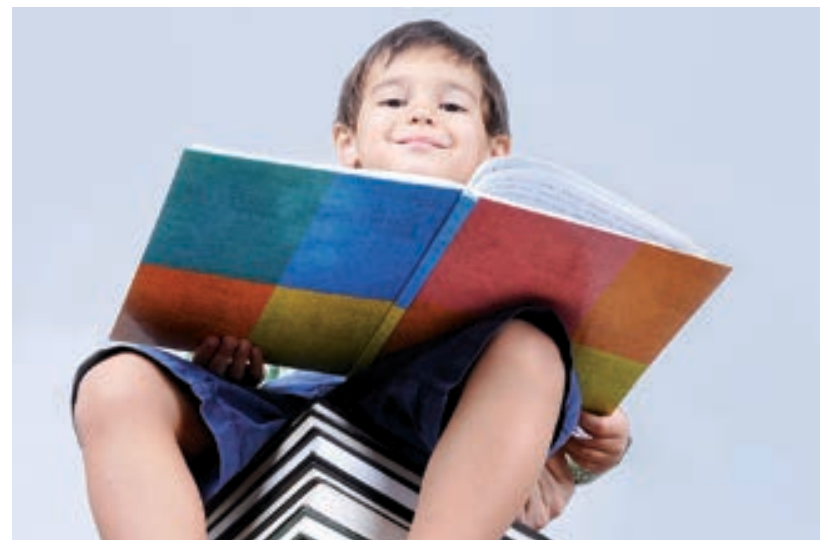

transformación social. En este proceso, además, enfatizan el compromiso del profesorado que en su conjunto comparte unos objetivos y una forma de trabajar común, así como el trabajo con la comunidad.

Finalmente, la labor desarrollada en la Fundació El Llindar de Cornellá del Llobregat está logrando prolongar las trayectorias educativas de muchas chicas y chicos que estaban condenados al fracaso. En lugar de quedarse en una perspectiva compensatoria, desde la Fundación han considerado que estos jóvenes tienen el mismo derecho al éxito educativo que nuestras hijas e hijos y por eso insisten en que tengan una experiencia educativa de éxito que les lleve a obtener el grado medio. Siguiendo la misma orientación que las otras experiencias, el énfasis está en ofrecer las mismas posibilidades a las personas con más dificultades desde una perspectiva del éxito, dejando atrás ocurrencias y opciones compensatorias que no han demostrado lograr superar las dificultades para estos colectivos.

En las siguientes páginas el lector o lectora podrá acceder con más detalle a algunas de estas experiencias, concretamente: el CEIP Antonio Machado; el IES Antonio Domínguez Ortiz; la Fundació El Llindar; la parroquia Santo Domingo de la Calzada; y la Asociación de Formación y Promoción Social Diversy y CEIP Prácticas n. ${ }^{\circ}$ I. En muy diversos ámbitos y desde la Educación Infantil, Primaria y Secundaria, la educación no formal o la formación para la inserción laboral, estas experiencias ofrecen un amplio abanico de cómo transformar las situaciones de dificultad hacia posibilidades de éxito para muchas personas. Como decía Paulo Freire (1997), a quien precisamente este número de la revista dedica su apartado "Grandes de la Educación" (escrito por su amiga y colaboradora Arantxa Ugartetxea), las personas somos seres de transformación y no de adaptación. El sentido de la educación reside en la transformación de las personas y del mundo, de sus barrios y pueblos y, en definitiva, en la transformación de sus vidas y la de sus hijos con el objetivo de tener un futuro mejor.

\section{Para saber más}

- Freire, P. (1997). A la sombra de este árbol. Barcelona: El Roure.

- Vygotsky, L. (1979). El desarrollo de los procesos psicológicos superiores. Barcelona: Crítica.

- Aubert, A.; Flecha, A.; García, C.; Flecha, R., y RACIONERO, S. (2008). Aprendizaje dialógico en la Sociedad de la Información. Barcelona: Hipatia.

\section{hemos hablado de:}

Éxito educativo; bases científicas; interacciones; participación de la comunidad; expectativas positivas; grupos vulnerables; transformación social.

Este artículo fue solicitado por PADRES Y MAESTROS en enero de 2014, revisado y aceptado en febrero de 2104 para su publicación. 